\title{
Where Culture and Metaphor Meet: Metaphoric Awareness in Comprehension of Culturally-Specific Idioms
}

\author{
Jasmina Jelčić Čolakovac \\ University of Rijeka, CROATIA \\ Faculty of Maritime Studies, Chair of Foreign Languages
}

Received: 10 July 2020 • Accepted: 18 October 2020 - Published Online: 30 October 2020

\begin{abstract}
The goal of the present study is to investigate whether the comprehension of oligosemic, i.e. culturally-specific (CS) idioms is raised with awareness of underlying conceptual metaphors (CMs) as seems to be the case with idioms motivated by metaphors (CM idioms). An experimental study was conducted involving the metaphor-aware Experimental group and the Control group which was unaware of the existence of CMs. Metaphoric awareness was achieved through brief 15 minute-long lessons on metaphor and underlying motivation. The Control participants were given general information on figurative language in order to ensure equality of input. The instrument containing 35 items was administered to both groups whereas the Experimental group was also provided the underlying CM motivation. An ANOVA test for repeated measures was used to compare CM data to CS data. There was a statistically significant effect of motivation on idiom comprehension, $\mathrm{F}(1,77)=67.203, \mathrm{p}=.000$ which suggests that $\mathrm{CM}$ idioms are better understood than CS idioms. The t-test results for the CS idioms indicate there is a significant difference between the Control and the Experimental group when it comes to the comprehension of CS idioms in favor of the Experimental participants; it seems the comprehension of CS idioms is raised with metaphoric awareness.
\end{abstract}

Keywords: idiom comprehension, conceptual metaphor, culturally-specific idioms, metaphoric awareness, EFL teaching.

\section{Introduction}

To speak figuratively aids language speakers in more ways than one. It is widely believed that figurative language exists to serve pragmatic rather than semantic functions since it offers an ornamental, optional way of utilizing speech (Katz et al., 1998: 2). However, a new perspective has emerged that sees it as a means of increasing a learner's proficiency and nativelike competence, which derives from the "appropriate selection of conventional phraseology" (Howarth, 1998: 31). We argue that to speak figuratively benefits native as well as second and foreign language speakers inasmuch as it provides speakers with an additional way of acquiring vocabulary. It also offers an insight into the culture the language originates from, which is particularly evident in ESL and EFL contexts (Boers, 2003; Deignan, 2003; Kövecses, 2005). The role of culture is also explored in the present study in which we aim to see whether conceptual metaphor (CM) instruction can be utilized in the teaching of those instances of language found tied to the L2 source culture. Before we turn to the role of culture in idiom comprehension, we will take a look at some of the conclusions drawn from research on metaphor in idiom comprehension.

(C) Authors. Terms and conditions of Creative Commons Attribution 4.0 International (CC BY 4.0) apply. Correspondence: Jasmina Jelčić Čolakovac, University of Rijeka, Faculty of Maritime Studies, Chair of Foreign Languages, 5100o Rijeka, Studentska 2, CROATIA. E-mail: jelcic@pfri.hr. 
- Grouping vocabulary has been proven to aid retention of vocabulary with second language learners.

- Significant differences are reported between metaphor-aided and metaphor-denied groups of learners.

- The idioms' underlying motivation seems to also heighten the understanding of culturallyspecific vocabulary items.

- The comprehension of culturally more salient expressions can be facilitated through instruction about their origin.

\section{Theoretical overview}

In the following paragraphs we will attempt to address the methods of raising metaphoric awareness in EFL (English as a Foreign Language) teaching and the role of culture in EFL idiom comprehension.

\subsection{Raising metaphoric awareness in the classroom}

The central idea around which the research for this study was developed is the fact that raising learners' awareness of conceptual metaphors (CMs) can facilitate their retention of the very vocabulary they motivate. Following Lakoff and Johnson's (1980) Conceptual Metaphor Theory (CMT), CM is seen as a universal mechanism of reasoning about the world that surrounds us. This mechanism thus motivates idioms as one type of linguistic expressions and if these expressions become frequently used by a group of people, they will become a part of the standardized phraseological corpus in a given language (Omazić, 2014: 30). We would agree with Deignan et al. (1997: 353) who said "students (...) are likely to achieve more if they are encouraged to consciously reflect on the metaphorical nature of language." Boers (2004: 211) listed five skills under the notion of metaphoric awareness:

(i) recognition of the pervasiveness of metaphor in everyday discourse; expressions;

(ii) recognition of specific $\mathrm{CMs}$ as the motivating mechanism behind figurative

(iii) awareness of the non-arbitrary nature of many figurative expressions;

(iv) awareness of the existence of cross-cultural differences between CMs;

(v) awareness of the existence of cross-cultural differences present in figurative expressions motivated by those CMs.

These skills can be used in the retention of figurative language in three ways: the semantic image behind an expression can be explained by explaining the etymological origin of the expression's literal meaning; learners can be encouraged to independently attempt to discern the meaning behind the expression; and expressions can be grouped according to underlying motivational mechanisms (Boers, 2004: 353). The latter has been employed in our study, since grouping vocabulary has been proven to aid retention of vocabulary, which is also pointed out by Kalyuga and Kalyuga (2008: 255) who recognize that "the presentation of vocabulary in chunks united by the same metaphorical themes can create a mental link and enhance learning by reducing a potential cognitive overload and the associated learning burden." Boers and Demecheleer (2001) proposed guidelines for the classroom in order to enhance the learners' awareness of the arbitrary nature of idioms and the existence of cross-cultural variation. In those cases, when one CM is absent from the learners' culture, but is present in the target culture, the authors suggest reminding the learners of the presence of the said CM in L2. Moreover, it can be fruitful to find L1 equivalents for idioms motivated by domains that are not represented in the 
source culture. Special attention needs to be given to the idioms, where there is a high risk of negative transfer occurring (e.g., the existence of equivalent expressions in the two cultures, but with different figurative meanings). Hypothesizing should be encouraged strongly on the part of the learner, since the problem-solving strategy leads to greater understanding. The teacher should serve as a beacon directing the students in the right direction in order to prevent them from getting sidetracked in their hypothesizing. Vivid imagery behind many idioms should be used to facilitate the retention of novel vocabulary, and etymological explanations should be provided where possible (Boers \& Demecheleer, 2001: 260-261).

The potential facilitation of raising metaphoric awareness in order to aid vocabulary processing, comprehension, and retention has been subject of a lot of investigations in EFL vocabulary teaching (Deignan et al., 1997; Boers, 2004; Boers et al., 2004; Beréndi et al., 2008; Geld et al., 2014). Various activities have been designed to serve an awareness-raising purpose in EFL classrooms, such as ecological niches, task-based activities, and role-play activities (Littlemore \& Low, 2006). Different factors involved in vocabulary teaching have been tested as variables, one of which is L1 transfer. Vasiljević (2011) included both CM awareness and L1 facilitation in order to test the way in which the Japanese learners' L1 exerted influence on their comprehension of English idioms. Three CMs were included in the study (IDEAS ARE FOOD, LOVE IS A JOURNEY, and LIFE IS A GAMBLING GAME) that were not present in the preteaching phase. The post-tests included a receptive task (a gap-fill exercise, where only the form needed to be recollected) and a productive task (a gap-fill exercise, where the participants were required to recall both the form and the meaning since the target idioms were not provided) (Vasiljević, 2011: 144-145). The data analysis pointed to the facilitative effect of CM upon idiom learning as well as the positive effect of presenting the translations of CMs and the target vocabulary in the learners' L1. Vasiljević' (2011) study follows the pattern of many other studies (for example, Kövecses \& Szabcó, 1996; Boers, 2000a; Samani \& Hashemian, 2012) in that it preteaches those examples of vocabulary that are going to be included in the testing. While a positive side of pre-teaching figurative language is the elimination of individual vocabulary knowledge that constitutes the items in focus, the downside of this approach is that it relies on the memory factor. Another study by Beréndi et al. (2008) included three separate experiments to determine if awareness of CMs helped language learners in their comprehension and retention of figurative expressions. The participants in their experiment were Hungarian students of English in their first year of studies at university. Both the Control and the Experimental groups were given a text in which idiomatic expressions were used in context. Afterwards, the idioms appeared in a list, where the students were required to provide translations of the idioms in question. The Experimental participants had the idioms in the list grouped according to the underlying conceptual metaphors, which were stated in the headings above each group of idioms, while the Control group was denied this (Beréndi et al., 2008: 76). They managed to confirm that metaphoric awareness of the underlying CMs helped learners in vocabulary retention. However, their consequent testings two days and five months after the initial testing showed that raising awareness of CMs might not prove sufficient to turn it into a conscious learning strategy that could contribute to learner autonomy. However, a closer look at the type of translations of the idioms the participants provided two days and five months later revealed that the task design did trigger some metaphor awareness after all, even though the participants did not seem to recall any instruction on CMs that was provided during the initial experiment. Kömür and Çimen (2013) did not opt for a oneeye opener about the existence of metaphor, as was the case with both Beréndi et al.'s (2008) and our own study, but they rather administered a pre- and post-test after holding a 10-hour long course aimed at raising students' metaphoric awareness of the multitude of CMs present in both their L1 (Turkish) and L2 (English). They also concluded that CM instruction in the classroom leads to greater retention of the instructed vocabulary.

Boers (2000a; 200ob) investigated the comprehension of idioms by EFL learners on multiple occasions. His (200ob) study dealt with idiom comprehension by EFL learners with the 
aid of $\mathrm{CM}$ and explanation of the literal meanings of the idioms. Both the control and the experimental groups in his experiment received interpretations of the target items; however, the control participants were given explanations of the items' figurative meanings (e.g., hurdle "difficulty, problem"), whereas the experimental group was given explanations of the literal meanings, i.e., source domains (e.g., hurdle "frame to be jumped over in athletics") (Boers, 200ob: 142). Boers (200ob: 143) obtained a statistically significant difference in results between the two groups, which is to suggest the experimental group managed to transfer patterns and judgments connected to the source domain onto the metaphoric meaning of the phrase. The author also investigated the issue of L1 in metaphoric instruction in EFL contexts. His participants were instructed to read a text designed for teaching purposes, which contained lexis related to THE BODY IS A CONTAINER FOR EMOTIONS and ANGER IS A HOT FLUID IN A CONTAINER metaphor. After the reading, both groups were given a cloze test to test for retention. The experimental group was statistically more likely to elicit a correct response suggesting "an awareness of the metaphoric themes behind the novel vocabulary can facilitate retention" (Boers, 200ob: 557).

\subsection{Culture in EFL idiom comprehension}

Metaphor and culture seem to be intertwined. Even if an expression is seen as originating from a particular domain of human activity (e.g., sail under false colors is derived from maritime), it can also be motivated by other imagery in the mind; this particular idiom can be seen as reflective of the metaphor SEEING IS KNOWING. Deignan (2003) lists several degrees of variation, where the most extreme case would be metaphors that are frequent in one language and rare or non-existent in another. Other degrees include metaphors, which are used in two languages but are far more frequent in one of the two languages, and metaphors that make use of the same source domain, but differ in details between languages (Deignan, 2003: 256-257). Boers (2003) identifies three types of cross-cultural variation in metaphor. The first type is differences between particular source-target mappings that have become conventional in observed cultures, such as baseball (also included in our study), which are more productive and conventional in American culture than in European. Another example of this type of variation is evident between French and English; French learners experience more difficulty in the interpretation of English idioms derived from maritime (a domain also included in our study as being culturally-specific) since this domain is underrepresented in the French culture (Boers 2003: 234-235). In these cases, Boers (2003) sees metaphoric awareness as serving the purpose of providing "a window onto a community's culture." The second type of variation occurs when there are differences observed in the valuejudgments associated with a certain metaphor or the appropriateness of that metaphor (Boers, 2003: 234-235). An example is provided using the GOVERNMENT IS A MACHINE metaphor and how it expresses different messages in different languages. For example, while Americans might think their government is impersonal and inflexible like a machine, speakers of other languages might look at their governments more leniently and perceive them as effective and smoothrunning and, thus, compare them to machines. The third case concerns the differences in pervasiveness of metaphor between different languages (Boers, 2003: 234-235). For example, Lakoff and Kövecses (1987) discuss ANGER IS A HEATED FLUID IN A CONTAINER as being pervasive in the American culture, and therefore, American English.

Cross-cultural variations in metaphoric conceptions have also been subject to investigation within the scope of CM's role in EFL teaching. Several examples can be found in literature that illustrate the example of cross-cultural differences in metaphoric entailments $(\mathrm{Yu}$, 1995; Kövecses, 2003; Charteris-Black, 2003; Chen, 2010; Li, 2010).The ANGER IS HEAT metaphor and its realizations on a more elaborate level (ANGER IS FIRE, ANGER IS A HEATED FLUID IN A CONTAINER) have been subject to cross-comparative investigations in English and Chinese (Yu, 1995; Chen, 2010; Li, 2010). Even though both languages perceive anger as fire, 
which is potentially harmful to those who get angry and also to those around them, in Chinese there is a more frequent utilization of body parts in figurative expressions, such as the heart, liver, and belly (Yu, 1995: 63). Furthermore, a lot of expressions in Chinese point to gas being used instead of liquid in the CONTAINER metaphor. This is a direct result of the difference in cultural systems of belief, where the Western culture oriented itself towards water as the source of life and Eastern mythology perceived air as the central element (Li, 2010). Boers and Demecheleer (2001) conducted research on French learners of English by testing their comprehension of selected idioms based on the imagery of hats, sleeves, ships, and food. They expected that idioms relating to a metaphoric theme that is more salient in the target culture would be "less easily 'guessable' to language learners" than those relating to themes that are equally or more salient in the L1 culture (Boers \& Demecheleer, 2001: 257). The results showed that French learners of English were more successful in translating those idioms relying on the two domains (sleeve and food) found more salient and thus more productive in the French culture (Boers \& Demecheleer, 2001: 258). On the other hand, hats and ships are frequently found domains in the English language, where a lot of expressions use the said imagery to convey meaning (e.g., pass the hat around, talk through one's hat, sail through something, etc.). The same authors conducted follow-up studies with the help of the software they developed (Idiom teacher) to facilitate the retention of culturally-specific idioms (Boers et al., 2004). In this study, the participants that were included were of Flemish Dutch origin and were tested on their retention of English idioms. The results were comparative with those obtained for the French students. Thirty-four expressions were identified from various domains, which were found less salient in the learners' L1 and for which the obtained results were lower than the overall score (Boers et al., 2004: 384). The authors used both culturally-specific idioms and phrases, which were found motivated by other mechanisms present in both languages, and even though culturally-specific idioms were understood less often than those motivated otherwise, the experimental learners to whom the origin of idioms was explained beforehand managed to score higher than the control participants who were denied such input.

\section{Methodology}

\subsection{Research framework}

In accordance with our research questions, two null hypotheses were set as follows:

$1 \mathrm{H}_{0}$ : There is no noticeable difference in the success of translation of CS idioms between the Control and the Experimental groups suggesting metaphoric awareness does not aid the comprehension of CS idioms.

$2 \mathrm{H}_{\mathrm{o}}$ : $\mathrm{CS}$ idioms are understood with the same ease as $\mathrm{CM}$ idioms suggesting $\mathrm{CM}$ motivation does not provide better ground for understanding figurative language among EFL learners.

Five CMs were chosen to be included in the testing as a means of control and their selection was based on the following two prevailing facts: (1) the metaphors were researched both by English and Croatian authors, and (2) they had been established as shared between the two languages. On the other hand, CS idioms were chosen from two culturally salient domains nautical and baseball - as representatives of British and American cultures respectively. The first step included the compilation of idiomatic expressions representative of the selected shared metaphors included in the administered instrument (a two-part questionnaire). By means of deduction, a list was produced containing idioms viable for the pilot study. The pilot study was then followed by the main study, which included a total of 150 participants all of whom were students of English as a foreign language at the Faculty of Maritime Studies, University of Rijeka. They were divided into Control and Experimental groups, and the selection was based on a random sample method. The testing was preceded by a 25 -minute introductory lesson on idiomatic 
language and idiomatic expressions. Extensive examples of idioms were drawn from both languages in order to ensure the participants' understanding of the concept of figurative vocabulary and idioms in general. In addition, the Experimental group was introduced to the concept of CMs and was given examples of metaphors motivating idioms in order to illustrate the connection between the two concepts. This was withheld from the Control group, which remained unaware of the connection between idioms and CMs (until after the testing had been completed). The questionnaire used to elicit the participants' responses included 35 items (25 items were motivated by shared metaphors and 10 items were English idioms from the cultural domains of maritime and baseball). Two versions of the questionnaire were designed, both of which consisted of two parts: Part 1 consisted of 25 idioms motivated by conceptual metaphors, and Part 2 consisted of 10 idioms from the domains of maritime and baseball. The Control group was administered a questionnaire that did not feature the items listed under corresponding conceptual metaphors and cultural domains, while the Experimental group was administered a questionnaire where the items were grouped according to the conceptual metaphors motivating the idioms. Both versions also included the translations of certain words mentioned in the provided context that were believed to be more or less unfamiliar to the participants and might, therefore, influence the results. The entirety of the research presented in this study was conducted in compliance with the principles of procedural ethics. Formal approval was sought and gained from the Ethical Committee at the Faculty of Maritime Studies in Rijeka, where both the pilot and the main studies were conducted.

\subsection{Coding procedure}

Based on the pilot group responses, a coding approach was developed for CM and CS idioms respectively. While designing the approach to coding the participants' responses, existing practices as well as the participants' own responses in this study were taken into account. The categories employed in our current were developed based mainly on the pilot study responses, and they were as follows:

(1) No translation provided: Coding the missing translations was equally as important as coding other categories because of the nature of the study. The aim was to see if underlying motivation exerted a higher response rate among Experimental group participants, thus suggesting higher learners' motivation among participants who at least tried to provide translations.

(2)Incorrect translation provided (INC TR): translations that do not reflect the correct target meaning of the idiom in question.

(3) Correct translation - no conceptual metaphor employed (COR NO CM): Translations are correct and in accordance with target meanings, but lack the obvious presence of metaphor use.

(4)Correct translation - target conceptual metaphor employed (COR TG CM): Translations are correct interpretations of idiom meanings and exhibit evident use of the specified underlying motivation.

(5) Correct translation - conceptual metaphor employed (COR CM): translations are correct, but are reflective of another metaphor and not the one specified in the testing.

In the case of CS idioms, categories (1), (2) and (3) were employed, since there were no CMs to aid the retention of CS idioms. The idioms grouped according to underlying etymology (domains of origin) were coded as belonging to one of the three possible categories, NO TR, INC TR, or COR NO CM. Since, by definition, the coding process is heavily reliant on the subjective impressions of the person performing the coding, the services of two additional coders were 
acquired for the purposes of this research. Both coders were holders of degrees in translation studies and had no previous insight into the research. The three different sets of data (the researcher's own categorization and two sets from independent coders) underwent inter-rater reliability tests in order to ensure data validity.

\section{Results}

In the following paragraphs we illustrate the data collected on the sample of 78 Control participants (mean age 20.06; range 18-26) and 72 Experimental participants (mean age 19.69; range 18-27) grouped according to inter- and intra- group statistical analyses.

\subsection{Group comparison}

Taking the combined frequencies for COR NO CM, COR TG CM, and COR CM categories into account, the Experimental group managed to outperform the Control group in terms of correctly provided translations for Part 2 items (415 as opposed to 269). Stated in percentages, the Experimental group managed to interpret CS idioms correctly in $37.77 \%$ of cases, while the Control group managed to do the same in $23.07 \%$ of cases. The total frequencies for each CS item and cultural domain are shown in Table 1, whereas in Table 2 means were compared for both Part 1 and Part 2 items.

An independent $t$-test was performed on the total means for CS idioms in an attempt to establish the significant difference between the results obtained for the Experimental $(\mathrm{N}=72)$ and Control group $(\mathrm{N}=78)$. The Experimental group obtained higher means on all of the $10 \mathrm{CS}$ idioms, with the most significant difference in scores obtained for the idiom keep on an even keel (1.01 for the Control group and 1.79 for the Experimental group). The slightest difference in scores was obtained for the idiom be off base (1.28 for the Control group in comparison to 1.42 for the Experimental group). These means were compared by means of a $t$-test the results of which are presented in Table 3.

There was a significant difference in the scores for the Control group $(\mathrm{M}=1.58, \mathrm{SD}=.35)$ and the Experimental group $(\mathrm{M}=2.03, \mathrm{SD}=.36)$ conditions; $t(148)=4.307, p=.000$. The $t$-test results for CS idioms indicate there is a significant difference ( $p$-value lower than .o1) between the Control and the Experimental group when it comes to the dependent variable measured (CS Idiom comprehension). The Experimental group yielded higher means in $\mathrm{CM}$ conditions than the Control group did in no CM conditions for CS idioms, which in turn allowed for $1 \mathrm{H}_{\mathrm{o}}$ to be rejected; the comprehension of CS idioms is raised with metaphoric awareness.

\subsection{Intra-group data}

An ANOVA test for repeated measures was used to compare CM data to CS data in order to deduce any significant difference between the two sets and cast light on whether CM idioms are understood better than CS idioms. The test was thus performed on the Control group means $(\mathrm{N}=78)$ obtained in Part 1 and Part 2 of the instrument (Table 4).

There was a statistically significant effect of motivation on idiom comprehension, $F(1,77)=67.203, p=.000$. This means that we can reject the null hypothesis in the case of the Control group and accept the alternative hypothesis stating that CM idioms are better understood than CS idioms. The test was repeated on the Experimental group data the results of which are reported in Table 5 . 
The test performed on the Experimental group means $(\mathrm{N}=72)$ obtained in Part 1 and Part 2 of the instrument suggests there was a statistically significant effect of motivation on idiom comprehension, $F(1,71)=69.576, p=.000$. This means we can reject the null hypothesis in the case of the Experimental group as well and accept the alternative hypothesis stating that the Experimental group participants understand CM idioms significantly better than CS idioms.

\section{Discussion}

Through an extensive data analysis, we managed to discard the null hypotheses in relation to our research questions. The results of our study suggest CM idioms are indeed understood more readily by EFL learners than idioms, which derive from a cultural domain not as salient in the learner's L1 culture. Both the Control and the Experimental groups managed to translate CM idioms (means of 1.58 and 2.03 respectively) with greater success than CS idioms (means of 1.17 and 1.60 respectively). In addition, these means were found to be statistically significant in the case of both groups (level of significance was obtained at a .oo level). This would suggest that those expressions, which are not motivated by an underlying CM, are more difficult to interpret than expressions, which can be traced back to the underlying CM. This hypothesis seems to hold ground even when EFL learners are not made aware of the existence of CMs (which the Control group's results corroborate).

\subsection{CM facilitation and culture-specific vocabulary}

The learners who were actively made aware of the existence of CMs in their language understood idioms better than the learners who were denied the same. A significant difference between results for CS idioms was obtained between the two groups at a .ooo level (Table 3). It is evident metaphor-aware students performed better with culturally-specific items than students who were denied the same tool. Making the learners aware of the idioms' underlying motivation seems to heighten their understanding of culturally-specific vocabulary items (Boers et al. 2004). We might argue, then, that raising metaphoric awareness contributes to overall understanding of the figurative language, even including examples that cannot be traced back to a certain CM. It seems that the awareness-raising lesson given to the Experimental students started a chain reaction that was not restricted to CS idioms alone; the strategy to look for the motivation beyond linguistic form was also stretched to CS idioms. However, these results might be suggestive of something else, which has to do with the underlying motivation of CS idioms. The reason why the Experimental group outperformed the Control group in CS idiom comprehension could be found in the fact that some CS idioms could also be brought into contact with specific CMs (and not necessarily their domains of origin). This would suggest that the etymological elaboration provided to the Experimental group lent little support to their comprehension of the target items. It was, rather, their heightened CM awareness that made them seek underlying CMs even for those culturally-specific items, which usually resist such attempts, since they are seen as motivated by cultural domains of human activities and not metaphorical conceptualizations. In other words, the Experimental group's dominant results for Part 2 items (Table 5) might be taken as evidence of CS idioms, which are somehow motivated by specific CMs. We have already mentioned that translations for CS idioms were categorized differently than in the case of CM idioms: the COR TG $\mathrm{CM}$ and COR CM categories were not included, since CS idioms are traditionally seen as resilient to CM conceptualization (Kövecses 2005). However, is this really the case? Our results could suggest that some idioms do lend themselves more readily to $\mathrm{CM}$ conceptualization than others, and it could also be the factor that resulted in the higher means obtained for those items in comparison to other culture-specific idioms. For example, sail under false colors might be reflective of the SEEING IS KNOWING metaphor; be on your beamends could be the product of the PEOPLE ARE MACHINES metaphor; blown off course could be motivated by DIFFICULTIES 
ARE IMPEDIMENTS TO MOTION, and the baseball idioms go to bat and step up to the plate might reflect one instantiation of the LIFE IS A SPORTING MATCH metaphor, i.e., PEOPLE ARE BASEBALL PLAYERS. The idiom be off base could thus be seen as reflective of the CONVERSATION IS A SPORTING MATCH instantiation of the same meatphor. If this were the case, it might be logical to assume that at least the Experimental group would translate the idioms that could potentially be motivated by a CM more sucessfully than other CS idioms, such as batten down the hatches or keep on an even keel, which directly reflect human activities in certain contexts. The data do not show sufficent consistency for the alternative interpretation of results to be taken as the primary reason for why some idioms were translated poorly; for example, even though the Experimental participants found batten down the hatches to be the most challenging to translate (mean .97), keep on an even keel was not among the CS idioms that obtained the lowest means in the Experiemntal group (mean 1.79). We conclude that some CS idioms might present a greater challenge than others due to an interplay of various factors. In the case of batten down the hatches, both the low-frequency word factor of the constituent hatches (Boers 2000a; Boers et al. 2004) and the idioms' resistence to any CM categorization might play a role.

Another factor which might play a role in experimental studies of similar scopes is input organization. In our study, the Experimental group was made aware of the source of origin for CS idioms, since their version of the questionnaire included the headings NAUTICAL PHRASES and BASEBALL PHRASES. The Control group's version, however, did not. The reason why the headings were included for Part 2 idioms was to retain the equality of input for the Experimental group. Other authors have also addressed the importance of equal input (Boers, 200ob; Geld et al., 2014), but in relation to inter-group rather than intra-group differences. No such methods of achieving equality of input between Control and Experimental participants were employed in our current research, although the order of the input was not changed and the idioms with the same underlying motivation still remained visually grouped in one larger textbox separated by space from the other idiom sets. The Control group was denied the headings for CS idioms in an attempt to equalize the input for Parts 1 and 2. Additionally, this was done in the specified manner in order to attempt to provide an answer to our research questions and see if the Experimental group was able to produce more correct translations for CS idioms than the Control group.

\subsection{Pitfalls to discerning motivation}

There are instances when any hinting at the phrases' motivation might not prove facilitative in its comprehension by language learners. The first of these situations includes lowfrequency keywords. If an idiom's component is a word that is not widely used in English or is not commonly taught in EFL contexts, then it might be difficult for the learner to decipher the meaning of the entire phrase (Boers et al., 2004: 378). For example, be in the doldrums contains the word doldrums, which is not just infrequently used, but also rather obsolete in English. We endeavored to eliminate the low-frequency keywords as a potential extraneous variable in our study by using a glossary. However, in spite of the inclusion of a glossary, unfamiliar keywords might have contributed to CS idioms' low means. In the Control group, the most poorly understood CS idioms were: batten down the hatches (.74), go to bat (.85), be on your beam ends (.92), and keep on an even keel (1.01). The CS idioms that obtained the lowest means in the Experimental group include: batten down the hatches (.97), go to bat (1.06), be off base (1.42), and be on your beam ends (1.42). As we can see, three of the idioms, which posed a challenge for both groups, include lowfrequency keywords: hatches, beam, and keel. It seems that any further implementation of CMs or etymological elaboration in classrooms would necessarily need to include pre-teaching relevant vocabulary, because even with additional learning tools such as CMs and referencing to the etymology of a phrase learners are still at an impasse when faced with idioms whose components feature a low-frequency lexeme. 
The second situation includes mostly culturally-specific idioms, where "the idiom may be derived from a source domain that is less salient in the learner's own culture" (Boers et al., 2004: 380). This was the case with the CS idioms included in our study (baseball and maritime expressions). Boers et al. (2004: 380) hypothesize that "the idioms derived from less familiar source domains will tend (...) to be less susceptible to dual coding and thus less easily remembered." If we take a closer look at the specific domains the idioms are derived from, such as maritime and baseball, we observe no relevant differences in the success of translation between the two source domains: both baseball and nautical idioms were equally difficult to interpret. It was our expectation that the nautical idioms might have presented a lesser challenge for two reasons. Firstly, Croatia is a coastal Mediterranean country, where maritime themes are very much entwined with the local cultures, especially in the Dalmatian, Istrian, and Kvarner regions, which is also evident in language production, where a lot of nautical expressions have taken root. Secondly, the participants of the main study were all students at the Faculty of Maritime Studies and thus more likely to be familiar with maritime vocabulary and everyday expressions. Our expectation was not met in this case: batten down the hatches, for example, obtained the lowest mean in both groups (mean .74 in the Control group and mean .97 in the Experimental group). It is closely followed by go to bat (mean .85 in the Control group and mean 1.06 in the Experimental group). The data thus show that the Control group translated baseball and nautical phrases with relatively the same success. However, they attempted to translate baseball phrases (96 NO TR responses) more frequently in comparison to nautical phrases (126 NO TR responses) (Table 1). The Control participants, therefore, attempted to translate baseball phrases more frequently than the nautical ones, but they also produced more incorrect translations in the case of baseball idioms (203 INC TR responses for baseball phrases, in comparison to 175 INC TR responses for nautical phrases). The statistics for the Experimental group tell us a slightly different story: they produced a total of 336 INC TR responses and 112 NO TR responses for CS idioms. This tells us that the Experimental group tended to produce more incorrect translations in both domains rather than leaving the answers blank. The significance of the discrepancy between these numbers obtained for the two groups is twofold. Firstly, the inter-group difference in the number of NO TR and INC TR responses suggests the Experimental students were more encouraged to attempt the translations of culturally-specific phrases than the Control students. Secondly, the inter-domain difference in favor of baseball phrases (which were more readily translated by both groups, unlike nautical phrases) indicates learners are more prone to attempt to translate phrases, which originate from domains more salient in their own culture (Boers et al., 2004: 380). This is not to suggest we believe baseball to be a salient domain in Croatian culture, but perhaps baseball is a cultural domain, which is more familiar to the younger generations of speakers, who have been exposed to some basic knowledge of the sport through cinematic art and other popular media devices frequently originating from the American culture. Their potential greater familiarity with baseball phrases rather than nautical ones encouraged them to attempt translations more often in the case of idioms connected to this domain; however, their insufficient knowledge of the same also resulted in a higher number of incorrect translations.

It might thus be concluded that neither the domain of origin nor the variety of English (British or American) was a significant factor when it came to idiom comprehension: EFL learners found baseball and nautical phrases to be equally challenging. However, it must be noted here that to claim responsibly that the two domains of origin are equally presented (or not) in both L1 and L2 would signify having to screen comparable dictionaries for idioms that can be retraced to the source domain under investigation and, additionally, use the language corpora with the purpose of counting the frequency of occurrence of the idioms, which were established as derived from the source domains subject to investigation (Boers et al., 2004: 377). These two complementary methods for determining whether particular source domains differ between linguistic communities were not employed in this research and, consequently, any firm claims about the included domains being equally present in Croatian and English cannot be made. 


\section{Conclusions}

All differences aside, our findings suggest that CS idioms, whose domains are less salient in the learners' L1, are understood more easily by students with raised CM awareness, i.e., the comprehension of culturally more salient expressions can be facilitated through instruction about their origin. Culture, it seems, plays an important role in idiom comprehension and culturally-motivated idioms present a greater challenge for the learners. The results show that metaphoric awareness not only aids the comprehension of those idioms motivated by shared CMs, but also CS idioms, the motivation of which cannot be elaborated through CMs, but rather by etymological elaboration. Our research aimed to prove the "worthiness" of CMs to be included in EFL teaching practices. Firstly, by offering learners an eye-opener about the presence of CMs in figurative expressions, we managed to yield a better comprehension rate for the target items. Without attempting to make general claims about CM universality, we do believe our findings can be interpreted in favor of a perspective, which perceives metaphoric awareness as a tool facilitating the comprehension of figurative vocabulary. Secondly, it would be interesting to see if CM awareness also influences retention. Even though we have reported on studies, which conducted post-tests to test for vocabulary retention, such experiments either lacked in experimental design or were conducted on too few participants for the results to be taken into consideration on a broader level of application. The short- and long-term effect of metaphoric instruction upon idiom retention could also be investigated more extensively with respect to idiom motivation to see if, perhaps, CS idioms are equally well remembered as CM idioms or if differences do exist.

\section{Acknowledgements}

This research did not receive any specific grant from funding agencies in the public commercial, or not-for-profit sectors.

The author declares no competing interests.

\section{References}

Beréndi, M., Csábi, S., \& Kövecses, Z. (2008). Using conceptual metaphors and metonymies in vocabulary teaching. In F. Boers \& S. Lindstromberg (Eds.), Cognitive linguistic approaches to teaching vocabulary and phraseology (pp. 65-99. Berlin-New York: Mouton de Gruyter.

Boers, F. (2000a). Metaphor awareness and vocabulary retention. Applied Linguistics, 21(4), 553-571.

Boers, F. (200ob). Enhancing metaphoric awareness in specialised reading. English for Specific Purposes, $19,137-147$.

Boers, F., \& Demecheleer, M. (2001). Measuring the impact of cross-cultural differences on learners' comprehension of imageable idioms. ELT Journal, 55(3), 255-262.

Boers, F. (2003). Applied linguistics perspectives on cross-cultural variation in conceptual metaphor. Metaphor and Symbol, 18(4), 231-238.

Boers, F. (2004). Expanding learners' vocabulary through metaphor awareness: What expansion, what learners, what vocabulary? In M. Achard \& S. Niemeier (Eds.), Cognitive linguistics, second language acquisition, and foreign language teaching (pp. 211-232). Berlin-New York: Mouton de Gruyter.

Boers, F., Demecheleer, M., \& Eyckmans, J. (2004). Cross-cultural variation as a variable in comprehending and remembering figurative idioms. European Journal of English Studies, 8(3), 375-388. 
Charteris-Black, J. (2003). Speaking with forked tongue: A comparative study of metaphor and metonymy in English and Malay phraseology. Metaphor and Symbol, 18(4), 289-310.

Chen, P. (2010). A cognitive study of "anger" metaphors in English and Chinese idioms. Asian Social Science, 6(8), 73-76.

Deignan, A., Gabryś, D., \& Solska, A. (1997). Teaching English metaphors using cross-linguistic awarenessraising activities. ELT Journal, 51(4), 352-360.

Deignan, A. (2003). Metaphorical expressions and culture: An indirect link. Metaphor and Symbol, 18(4), 255-271.

Geld, R., Tadić, T., \& Stanojević, M.-M. (2014). Uloga konceptualne metafore u poučavanju vokabulara kod videćih i slijepih učenika engleskog jezika [The role of conceptual metaphor in teaching vocabulary to sighted and blind learners of English]. In M.-M. Stanojević (Ed.), Metafore koje istražujemo (pp. 255-277). Zagreb: Srednja Europa.

Howarth, P. (1998). Phraseology and second language proficiency. Applied Linguistics, 19(1), 24-44.

Kalyuga, M., \& Kalyuga, S. (2008). Metaphor awareness in teaching vocabulary. Language Learning Journal, 36(2), 249-257.

Katz, A. N., Cacciari, C., Gibbs, R. W., \& Turner, M. (1998). Figurative language and thought. New YorkOxford: Oxford University Press.

Kömür, Ş., Çimen, Ş. S. (2013). Using conceptual metaphors in teaching idioms in a foreign language context. Sosyal Ve Beşeri Bilimler Araştirmalari Dergisi, 23, 205-222.

Kövecses, Z., \& Szabcó, P. (1996). Idioms: A view from cognitive semantics. Applied Linguistics, 17(3), 326355.

Kövecses, Z. (2003). Language, figurative thought, and cross-cultural comparison. Metaphor and Symbol, 18(4), 311-320.

Kövecses, Z. (2005). Metaphor in culture: Universality and variation. Cambridge: Cambridge University Press.

Lakoff, G., \& Johnson, M. (1980). Metaphors we live by. Chicago-London: University of Chicago Press.

Lakoff, G., \& Kövecses, Z. (1987). The cognitive model of anger inherent in American English. In D. Holland \& N. Quinn (Eds.), Cultural models in language and thought (pp. 195-221). Cambridge: Cambridge University Press.

Li, X. (2010). Conceptual metaphor theory and teaching of English and Chinese idioms. Journal of Language Teaching and Research, 1(3), 206-210.

Littlemore, J., \& Low, G. (2006). Metaphoric competence, second language learning, and communicative language ability. Applied Linguistics, $27(2), 268-294$.

Omazić, M. (2014). Konceptualna metafora u frazeologiji [Conceptual metaphor in phraseology]. In M.-M. Stanojević (Ed.), Metafore koje istražujemo (pp. 27-45). Zagreb: Srednja Europa.

Samani, E. R., \& Hashemian, M. (2012). The effect of conceptual metaphors on learning idioms by L2 learners. International Journal of English Linguistics, 2(1), 249-256.

Stanojević, M.-M. (2013). Konceptualna metafora: temeljni pojmovi, teorijski pristupi $i$ metode [Conceptual metaphor: basic concepts, theoretical approaches and methods]. Zagreb: Srednja Europa.

Vasiljević, Z. (2011). Using conceptual metaphors and L1 definitions in teaching idioms to non-native speakers. The Journal of Asia TEFL, 8(3), 135-160.

$\mathrm{Yu}, \mathrm{N}$. (1995). Metaphorical expressions of anger and happiness in English and Chinese. Metaphor and Symbol, 10(2), 59-92. 
Appendix

Table 1. Response frequencies for CS idioms across the three coding categories

\begin{tabular}{|c|c|c|c|c|c|c|}
\hline \multirow[b]{2}{*}{ Item } & \multicolumn{3}{|c|}{ Control group } & \multicolumn{2}{|c|}{$\begin{array}{l}\text { Experimental } \\
\text { group }\end{array}$} & \multirow[b]{2}{*}{$\begin{array}{r}\text { COR } \\
\text { NO CM }\end{array}$} \\
\hline & NO TR & $\begin{array}{l}\text { INC } \\
\text { TR }\end{array}$ & $\begin{array}{r}\text { COR } \\
\text { NO CM } \\
\end{array}$ & NO TR & $\begin{array}{l}\text { INC } \\
\text { TR }\end{array}$ & \\
\hline $\begin{array}{r}\text { batten down the } \\
\text { hatches } \\
\text { keep on an even }\end{array}$ & 28 & 46 & 4 & 12 & 55 & 5 \\
\hline $\begin{array}{r}\text { keel } \\
\text { sail under false }\end{array}$ & 27 & 37 & 14 & 9 & 30 & 33 \\
\hline $\begin{array}{r}\text { colors } \\
\text { be on your }\end{array}$ & 19 & 28 & 31 & 6 & 28 & 38 \\
\hline $\begin{array}{l}\text { beam ends } \\
\text { be blown off }\end{array}$ & 36 & 27 & 15 & 18 & 30 & 24 \\
\hline course & 16 & 37 & 25 & 7 & 22 & 43 \\
\hline Total & 126 & 175 & 89 & 52 & 165 & 143 \\
\hline $\begin{array}{r}\text { have two strikes } \\
\text { against you }\end{array}$ & 18 & 42 & 18 & 11 & 27 & 34 \\
\hline go to bat & 26 & 45 & 7 & 20 & 40 & 12 \\
\hline throw a curve & 14 & 30 & 34 & 8 & 22 & 42 \\
\hline $\begin{array}{l}\text { step up to the } \\
\text { plate }\end{array}$ & 20 & 46 & 12 & 13 & 37 & 22 \\
\hline be off base & 18 & 40 & 20 & 8 & 45 & 19 \\
\hline Total & 96 & 203 & 91 & 60 & 171 & 129 \\
\hline Grand total & 222 & 378 & 180 & 112 & 336 & 272 \\
\hline
\end{tabular}

Table 2. A comparison of means for the 35 items for the Control and Experimental groups

\begin{tabular}{r|ccccccccc}
\hline Item & \multicolumn{3}{|c}{ Control (N=78) } & \multicolumn{3}{c}{$\begin{array}{c}\text { Experimental } \\
(\mathbf{N = 7 2 )}\end{array}$} & \multicolumn{3}{c}{ Total (N=150) } \\
\hline & $\mathrm{M}$ & $\mathrm{SD}$ & $\mathrm{SE}$ & $\mathrm{M}$ & $\mathrm{SD}$ & $\mathrm{SE}$ & $\mathrm{M}$ & $\mathrm{SD}$ & $\mathrm{SE}$ \\
let off steam & 2.21 & .76 & .09 & 2.57 & .71 & .08 & 2.38 & .76 & .06 \\
add fuel to the fire & 2.19 & .81 & .09 & 2.56 & .67 & .08 & 2.37 & .76 & .06 \\
fan the flames & 1.54 & .62 & .07 & 2.25 & .78 & .09 & 1.88 & .79 & .06 \\
take the heat out of & & & & & & & & & \\
something & 1.59 & .61 & .07 & 1.75 & .75 & .09 & 1.67 & .68 & .06 \\
get hot under the collar & 1.22 & .71 & .08 & 1.31 & .91 & .11 & 1.26 & .82 & .07 \\
blow your stack & 1.37 & .87 & .10 & 1.94 & .85 & .10 & 1.65 & .91 & .07 \\
hit the ceiling & 1.58 & .61 & .07 & 1.97 & .80 & .10 & 1.77 & .74 & .06 \\
have kittens & .96 & .76 & .09 & 1.71 & 1.08 & .13 & 1.32 & 1.00 & .08 \\
blow your top & 1.33 & 1.00 & .11 & 1.97 & 1.14 & .13 & 1.64 & 1.11 & .09
\end{tabular}




\begin{tabular}{|c|c|c|c|c|c|c|c|c|c|}
\hline burst a blood vessel & 1.74 & .81 & .09 & 2.01 & .94 & .11 & 1.87 & .89 & .07 \\
\hline spin your wheels & 1.41 & .73 & .08 & 1.69 & 1.04 & .12 & 1.55 & .90 & .07 \\
\hline hit a dead end & 1.68 & .99 & .11 & 2.51 & .89 & .11 & 2.08 & 1.03 & .08 \\
\hline at a crossroads & 1.77 & .77 & .09 & 2.56 & .73 & .09 & 2.15 & .85 & .07 \\
\hline go off the track & 1.87 & 1.06 & .12 & 2.36 & .98 & .12 & 2.11 & 1.05 & .09 \\
\hline have a head start in life & 1.38 & .73 & .08 & 1.64 & .89 & .11 & 1.51 & .82 & .07 \\
\hline be on the warpath & 1.09 & .63 & .07 & 1.33 & .90 & .11 & 1.21 & .78 & .06 \\
\hline $\begin{array}{r}\text { shoot down someone's } \\
\text { arguments }\end{array}$ & 1.91 & .91 & .10 & 2.24 & .91 & .11 & 2.07 & .92 & .08 \\
\hline $\begin{array}{r}\text { cross swords with } \\
\text { someone }\end{array}$ & 1.62 & .87 & .10 & 2.15 & .90 & .11 & 1.87 & .92 & .08 \\
\hline fight a losing battle & 1.99 & .93 & .11 & 2.42 & .93 & .11 & 2.19 & .95 & .08 \\
\hline fight to the last ditch & 2.55 & .68 & .08 & 2.82 & .66 & .08 & 2.68 & .68 & .06 \\
\hline $\begin{array}{r}\text { be up the creek without } \\
\text { a paddle }\end{array}$ & 1.35 & .82 & .09 & 1.61 & .96 & .11 & 1.47 & .90 & .07 \\
\hline hit a brick wall & 1.35 & .91 & .10 & 2.25 & 1.07 & .13 & 1.78 & 1.09 & .09 \\
\hline fight an uphill battle & 1.10 & .78 & .09 & 1.54 & .95 & .11 & 1.31 & .89 & .07 \\
\hline face hurdles & 1.18 & 1.00 & .11 & 1.64 & 1.13 & .13 & 1.40 & 1.09 & .09 \\
\hline $\begin{array}{l}\text { be caught between a } \\
\text { rock and a hard place }\end{array}$ & 1.68 & .95 & .11 & 2.10 & .91 & .11 & 1.88 & .95 & .08 \\
\hline $\begin{array}{r}\text { batten down the } \\
\text { hatches }\end{array}$ & .74 & .71 & .08 & .97 & .67 & .08 & .85 & .70 & .06 \\
\hline keep on an even keel & 1.01 & 1.04 & .12 & 1.79 & 1.16 & .14 & 1.39 & 1.16 & .10 \\
\hline sail under false colors & 1.55 & 1.25 & .14 & 1.97 & 1.13 & .13 & 1.75 & 1.20 & .10 \\
\hline be on your beam ends & .92 & 1.11 & .13 & 1.42 & 1.20 & .14 & 1.16 & 1.18 & .10 \\
\hline be blown off course & 1.44 & 1.15 & .13 & 2.10 & 1.14 & .13 & 1.75 & 1.19 & .10 \\
\hline have two strikes against & & & & & & & & & \\
\hline you & 1.23 & 1.06 & .12 & 1.79 & 1.20 & .14 & 1.50 & 1.16 & .09 \\
\hline go to bat & .85 & .82 & .09 & 1.06 & .98 & .12 & .95 & .90 & .07 \\
\hline throw a curve & 1.69 & 1.21 & .14 & 2.06 & 1.16 & .14 & 1.87 & 1.20 & .10 \\
\hline step up to the plate & 1.05 & .94 & .11 & 1.43 & 1.11 & .13 & 1.23 & 1.04 & .09 \\
\hline be off base & 1.28 & 1.09 & .12 & 1.42 & 1.00 & .12 & 1.35 & 1.05 & .09 \\
\hline
\end{tabular}


Table 3. $t$-test results comparing the Control (N=78; $\mathrm{CM}$ idioms: $\mathrm{M}=1.58, \mathrm{SD}=.35$; $\mathrm{CS}$ idioms: $\mathrm{M}=1.17, \mathrm{SD}=.59)$ and Experimental $(\mathrm{N}=72 ; \mathrm{CM}$ idioms: $\mathrm{M}=2.03, \mathrm{SD}=.36$; $\mathrm{CS}$ idioms: $\mathrm{M}=1.60$,

$\mathrm{SD}=.60$ ) groups on Idiom Comprehension with respect to underlying motivation

\begin{tabular}{|c|c|c|c|c|c|c|c|c|c|}
\hline \multicolumn{10}{|c|}{ Independent $t$-test } \\
\hline & & $\begin{array}{l}\text { ne's } \\
\text { or } \\
y \text { of } \\
\text { ces }\end{array}$ & \multicolumn{7}{|c|}{ t-test for Equality of Means } \\
\hline & \multirow[b]{2}{*}{$\mathbf{F}$} & \multirow[b]{2}{*}{ Sig. } & \multirow[b]{2}{*}{$\mathbf{t}$} & \multirow[b]{2}{*}{ df } & \multirow{2}{*}{$\begin{array}{l}\text { Sig. } \\
(2- \\
\text { tailed) }\end{array}$} & \multirow{2}{*}{$\begin{array}{c}\text { Mean } \\
\text { Differ } \\
\text { ence }\end{array}$} & \multirow{2}{*}{$\begin{array}{l}\text { Std. Error } \\
\text { Difference }\end{array}$} & \multicolumn{2}{|c|}{$\begin{array}{l}\text { 95\% Confidence } \\
\text { Interval of the } \\
\text { Difference }\end{array}$} \\
\hline & & & & & & & & Lower & Upper \\
\hline $\begin{array}{c}\mathrm{CS} \\
\text { idioms* }\end{array}$ & 200 & .655 & 4.307 & 148 & .000 & .423 & .098 & .228 & .617 \\
\hline $\begin{array}{r}\mathrm{CM} \\
\text { idioms* }\end{array}$ & 956 & .330 & 7.657 & 148 & .000 & .449 & .058 & .333 & .566 \\
\hline
\end{tabular}

* Equal variances assumed.

** $p<.001$

Table 4. ANOVA test results for Control group means according to Motivation: CM idioms $(\mathrm{N}=78, \mathrm{M}=1.58, \mathrm{SD}=.35)$ and $\mathrm{CS}$ idioms $(\mathrm{N}=78, \mathrm{M}=1.17, \mathrm{SD}=.59)$

\begin{tabular}{|c|c|c|c|c|c|c|c|}
\hline \multicolumn{8}{|c|}{ Tests of Within-Subjects Effects - Control group } \\
\hline Source & Type III Sum & quares & df & $\begin{array}{r}\text { Mean } \\
\text { Square }\end{array}$ & $\mathbf{F}$ & Sig. & $\begin{array}{c}\text { Partial } \\
\text { Eta } \\
\text { Squared }\end{array}$ \\
\hline \multirow{4}{*}{ Motivation } & $\begin{array}{l}\text { Sphericity } \\
\text { Assumed }\end{array}$ & 6.531 & 1 & 6.531 & 67.203 & .000 & .466 \\
\hline & $\begin{array}{l}\text { Greenhouse- } \\
\text { Geisser }\end{array}$ & 6.531 & 1 & 6.531 & 67.203 & .000 & .466 \\
\hline & Huynh-Feldt & 6.531 & 1 & 6.531 & 67.203 & .000 & .466 \\
\hline & Lower-bound & 6.531 & 1 & 6.531 & 67.203 & .000 & .466 \\
\hline \multirow{4}{*}{$\begin{array}{c}\text { Error } \\
\text { (Motivation) }\end{array}$} & $\begin{array}{l}\text { Sphericity } \\
\text { Assumed }\end{array}$ & 7.483 & $7^{7}$ & .097 & & & \\
\hline & $\begin{array}{l}\text { Greenhouse- } \\
\text { Geisser }\end{array}$ & 7.483 & $7^{7}$ & .097 & & & \\
\hline & Huynh-Feldt & 7.483 & $7^{7}$ & .097 & & & \\
\hline & Lower-bound & 7.483 & $7^{7}$ & .097 & & & \\
\hline
\end{tabular}

Computed using $p=.05$. 
Table 5. ANOVA test results for Experimental group means according to Motivation: CM idioms $(\mathrm{N}=72, \mathrm{M}=2.03, \mathrm{SD}=.36)$ and $\mathrm{CS}$ idioms $(\mathrm{N}=72, \mathrm{M}=1.60, \mathrm{SD}=.60)$

\begin{tabular}{|c|c|c|c|c|c|c|c|}
\hline \multicolumn{8}{|c|}{ Tests of Within-Subjects Effects - Experimental group } \\
\hline Source & \multicolumn{2}{|c|}{$\begin{array}{c}\text { Type III Sum of } \\
\text { Squares }\end{array}$} & df & $\begin{array}{l}\text { Mean } \\
\text { Square }\end{array}$ & $\mathbf{F}$ & Sig. & $\begin{array}{c}\text { Partial } \\
\text { Eta } \\
\text { Squared }\end{array}$ \\
\hline \multirow{4}{*}{ Motivation } & $\begin{array}{l}\text { Sphericity } \\
\text { Assumed }\end{array}$ & 6.847 & 1 & 6.847 & 69.576 & .000 & .495 \\
\hline & $\begin{array}{l}\text { Greenhous } \\
\text { e-Geisser }\end{array}$ & 6.847 & 1 & 6.847 & 69.576 & .000 & .495 \\
\hline & $\begin{array}{l}\text { Huynh- } \\
\text { Feldt }\end{array}$ & 6.847 & 1 & 6.847 & 69.576 & .000 & .495 \\
\hline & $\begin{array}{l}\text { Lower- } \\
\text { bound }\end{array}$ & 6.847 & 1 & 6.847 & 69.576 & .000 & .495 \\
\hline \multirow{4}{*}{$\begin{array}{l}\text { Error } \\
\text { (Motivatio } \\
\mathrm{n})\end{array}$} & $\begin{array}{l}\text { Sphericity } \\
\text { Assumed }\end{array}$ & 6.987 & 71 & .098 & & & \\
\hline & $\begin{array}{l}\text { Greenhous } \\
\text { e-Geisser }\end{array}$ & 6.987 & 71 & .098 & & & \\
\hline & $\begin{array}{l}\text { Huynh- } \\
\text { Feldt }\end{array}$ & 6.987 & 71 & .098 & & & \\
\hline & $\begin{array}{l}\text { Lower- } \\
\text { bound }\end{array}$ & 6.987 & 71 & .098 & & & \\
\hline
\end{tabular}

Computed using $\mathrm{p}=.05$. 